\title{
España (y Feijoo) en motivos culturales y eruditos portugueses del siglo XVIII
}

\author{
por GIUSEPPE CARLO ROSSI \\ Catedrático del lastituto Universitario Oriental de Nápoles
}

Es conocida la relativa escasez, cualitativa y cuantitativa, de contactos culturales entre España y Portugal, países que con frecuencia se han mostrado sorprendentemente lejanos uno de otro, con un alejamiento que puede parecer desconcertante y no fácilmente comprensible ni explicable para quien no tenga mucha familiaridad con las vicisitudes de la Península Ibérica. Y en el libro ideal, que todavía está por escribirsè, sobre la historia de dichos contactos, por muy escasos que hayan sido, el capítulo que se refiere al siglo xvin nos parece que no resultaría entre los más sustanciosos: motivos diversos y de varia índole, propios de Portugal (de naturaleza política, psicológica, etc.) o propios de toda Europa (reacción al barroco, etc.), confluyeron para acelerar, en aquel siglo, la liquidación de la presencia, de indiscutible peso y de indiscutible significado, que España había tenido también en Portugal en el siglo precedente.

También Portugal, de hecho, con el triunfo del espíritu francés del iluminismo, y con el triunfo de las formas italianas del arcadismo, halló 
estímulo para alejarse, y muy rápidamente, en el Setecientos, de la atmósfera española: en un primer momento limitando sus relaciones a aspectos —diríamos- negativos, de reacción, como, por ejemplo, de oposición al gongorismo; como se nota en el aburrido pero útil documento que nos ha dejado Frei Lucas de Santa Catarina, el Serão Politico-Abuso Emendado con el cual se abre aquel siglo (1704), ${ }^{\dagger}$ o en el que nos dejó Leitão Ferreira con su Nova Arte de Conceitos (1718-1721) que, aun prestando todavía oídos a la lección de Gracián, lanza sus saetas contra Góngora y contra sus imitadores portugueses; en un segundo momento nivelando su interés por la cultura española con el interés por las demás culturas, como se nota en el Arte Poética (1766) de Francisco José Freire, en la que la teoría poética de Luzán, evidentísima, ha sido aprovechada pero dentro del espíritu neoclásico que pone en el mismo nivel a Boileau y a Voltaire, a Addison y a Pope, y, por encima de todos ellos, a Muratori, bajo la autorizada supervisión simbólica de Aristóteles y de Horacio. Y este escaso conocimiento, por parte de los portugueses, de la vida cultural española de aquel tiempo y, más aún, su poco deseo de tomarla en consideración, resulta todavía más impresionante por tratarse del siglo en que el iluminismo se propuso, incluso formalmente, llevar la curiosidad y la búsqueda de noticias y de conocimientos por encima de cualquier confín geográfico o cultural.

En el espíritu de estas consideraciones preliminares está impostado este nuestro presente estudio que trata de fijar lo que hay de español en la obra que revolucionó notoriamente el pensamiento pedagógico portugués del Setecientos a la luz de las corrientes filosófico-culturales de la Europa de aquel entonces, es decir en la obra que introdujo, con audacia y con insistencia que cayeron como una pesada piedra en el estanque muerto de la vida intelectual portuguesa de mediados de aquel siglo, una semilla que daría sus frutos: cl Verdadeiro método de estudar del padre oratoriano Luís António Verney, publicado en 1746 (con una inmediata reedición al año siguiente) bajo el seudónimo de un fraile "Barbadinho» de la Congregación italiana de la misma Orden; seudónimo que pretendía alejar de la cabeza del autor los rayos que, sin duda, habrían de lanzársele por la audacia de sus ideas. Es bien sabido lo mucho que se sirvieron de dicha obra las pocas personalidades portuguesas de aquel tiempo que estaban decididas a romper con el pasado, en primer término Pombal. Con la metodicidad con que están escritas (a

1. José Ares Montes ha demostrado las analogfas de esta obra con el Deleytar aprovechando de Tirso de Molina (véase: "Cervantes en la literatura portuguesa del siglo XVII", en los Anales Cervantinos, II, 1952). 
un supuesto amigo, doctor de la Universidad de Coimbra) cada una de las dieciséis Cartas que constituyen la obra, es decir, con el aspecto negativo de cada uno de los argumentos tratados (crítica contra la orientación de aquel tiempo a este respecto) y con el aspecto positivo (propuestas de reforma contra aquella orientación), Verney logró dar un orden riguroso y una fecunda concatenación de ideas a la larga serie de fuentes, de todo país y de todo tiempo, de las cuales se sirvió en su exposición, hasta el punto de presentársenos hoy —alejada ya la polémica que hizo difícil durante mucho tiempo el comprender la sustancia de su obra-como un auténtico hombre del Setecientos, con sus ideas extremadamente claras y con su constante buen sentido y feliz espíritu práctico. Del Verdadeiro método de estudar se tuvo en consideración predominante, si no exclusiva, hasta llega ra nuestro siglo, el lado negativo, es decir, la crítica contra el mundo del pensamiento y de los estudios de su época, en detrimento del lado positivo, es decir, de la propuesta de reformas. Pero hoy que esta obra no se lee ya como antes por lo menos con un poco de resentimiento polémico, o con jacobina complacencia, sino que se la considera por el contrario, en su aspecto más interesante y genuino, de hábil y fructífera capacidad de asimilación y buen uso de ajenas fuentes de pensamiento, con la consiguiente revalorización de la importancia que tuvo la obra en la historia de la cultura, y sobre todo en los capítulos de las innovaciones, de la vida espiritual de su pueblo, se nos ocurre la curiosidad de ver qué puesto ocupa España en el conjunto de los muchos países de cuya actividad espiritual se aprovechó Verney.

Y hay que decir ya desde ahora que, a quien lea el Verdadeiro método de estudar con la finalidad arriba indicada, en esta obra, dentro del espíritu de familiaridad, no frecuente en el Portugal de principios del Setecientos, con tanta cultura extranjera, lo primero que salta a la vista es, por un lado, la presencia sólo muy relativa de España; y, por otra parte, la actitud generalmente de cautela, e incluso de sospecha, y hasta de abierta crítica y repulsa hacia ella (cuando está presente), por parte de Verney.

En las tres primeras de las dieciséis Cartas (las que tratan del estudio de la lengua portuguesa, de la gramática latina, y de la latinidad) España no aparece para nada, ni siquiera a través de un nombre o de un acontecimiento, por secundario que fuera. En la cuarta (la Carta en que se plantea el problema del estudio del griego y del hebreo) la fugaz referencia que hace Verney a la revisión hecha por Arias Montano de la Biblia del dominico italiano Sante Pagnino, no es harina del costal de Verney; la ha traducido de Lamy. La primera vez que Verney trata explícitamente de los españoles en general o de uno de ellos en particular (el agustino 
Bartolomé de los Ríos - y Alarcón-, predicador de Felipe IV), lo hace en la Carta $V$ (que trata de la retórica); al examinar la oratoria sagrada portuguesa, cuando se dispone a condenar $-\mathrm{y}$ esto era entonces una novedad- la predicación barroca en general, y la del P. António Vieira en particular, el escritor se detiene en el predicador español para servirse de él como ejemplo particularmente comprobador del uso arbitrario de aquellos «conceitos predicáveis» sobre los cuales el Seiscientos se afanó en escribir gruesos volúmenes para enseñar a caminar... contra la lógica.

Pero la crítica contra aquel fraile del Seiscientos es una bagatela comparada con la crítica demoledora que, contra el soneto "de certo Espanhol, que descrevia um nariz grande, o qual, depois de ter dito muita coisa do dito nariz, conclui desfazendo quanto encarecera", ${ }^{2}$ hace Verney en la Carta siguiente, la VI (que se ocupa también de la retórica con la intención, esta vez, de dar un «Plano duma retórica moderna»), arremetiendo ahora, más aún que contra los oradores y los historiadores, contra los poetas (los cuales, a causa de la rima o de la cantidad del verbo, dicen mil cosas «ou mal ditas, ou mal aplicadas»). Y por los dos tercetos de dicho soneto, que el setecentista portugués reproduce íntegramente, añadiendo un comentario significativo al cuarteto que las precede («Depois dos quatro versos antecedentes, em que exagerava terrivelmente o tal nariz, sai com uma friolera que destrui tudo»), se descubre que dicho "certo Espanhol» es nada menos que Francisco de Quevedo, y que el soneto es uno de los más famosos no sólo de él sino de todo el barroco español : "Erase un hombre a una nariz pegado ". ${ }^{3}$ Lo cual induce a pensar o que Verney no había oído antes de entonces el nombre de Quevedo - o al oírlo lo había tomado por un poetastro cuyo nombre apenas oído se olvida- o que su desprecio hacia Quevedo era tan grande que se portaba con él como si lo ignorara... Y lo mismo en el primer caso que en el segundo es como para quedarse impresionados... ${ }^{4}$ Menos mal que, aunque sea haciendo una añadidura por su cuenta, Verney reconoce la agudeza de Quevedo en otra ocasión, cuando habla de un "engenho

2. Citamos el Verdadeiro método de estudar por la edición en cinco volúmenes, hecha por António Salgado Júnior, de Lisboa, Livraria Sá da Costa Editora, 1949-1952. La cita está tomada de ob. cit., II, p. 84.

3. La cosa que más molestaba a Verney era por lo lanto la pretensión -que atribuye a Ouevedode querer hacer creer que pueda existir una nariz "maior que todo o corpow; es, evidentemente, la reacción del setecencista que obedece a la exigencia de lo verosímil, de la "raison".

4. En el capítulo sobre los "Ornamentos", en la misma Carta, demoliendo una oración fúnebre portuguesa, y arremetiendo contra la mala ralea de los panegiristas que, mientras parecen cultisimos, dejan suponer que no han leído lo que citan, y que toman sus citas de los varios Theatrum vitae, etc., cita también el Teatro de los Dioses, evidentemente de Fray B. de Vitoria, y se digna nombrar también a España, junto a Italia, Países Bajos, Francia y Alemania, como países a cuyas universidades hace alusión indistinta aquel panegirista portugués para demostrarse persona culta. 
espanhol» que dijo "que metade do mundo vive da opinião da outra metade $^{5}$ (a lo que él añade: «e eu cuido que se pode prosseguir adiante e dizer que, de dez mil hc...ens, 9.999 vivem da opinião do décimo mil»), siempre que, como parece que puede suponerse dado el género por lo menos aparentemnte paradójico, se trate de Quevedo.

Hay que decir, sin embargo, que esta Carta VI - que es una de las más interesantes para nuestro estudio- presenta también un momento lisonjero, mejor dicho doblemente lisonjero, para España, porque, al hacer suyo el pensamiento de Lamy (en el capítulo que trata del "método de persuadir»), según el cual un modo seguro de despertar la atención es el «não mostrar o objecto que se propõe, se não quando a atenção já não é necessária», ${ }^{6}$ Verney sale con un categórico e inesperado elogio nada menos que de Gracián, de cuyo pensamiento no se ocupa, pero cuyo método aprueba, y precisamente a propósito de El Criticón:

"O mesmo Gracián, no seu Criticón, engenha de sorte a narracão das figuras que introduz, que acaba o capítulo quando se há-de explicar algum grande facto, e, reservando a solução para o seguinte, conduz o leitor, desde o principio até o fim, sempre com curiosidade de ler. p $^{7}$

Pero en otra ocasión le toca a Verney hablar de El Criticón, y entonces su opinión sobre el mismo es la previsible de un setecentista contra el Seiscientos : habla, efectivamente, de él en la Carta dedicada al estudio de la poesía (la séptima) en la cual, en el capítulo que trata de las "Composições fundadas na chamada Agudeza», al censurar las «insípidas ridicularias» del "mau engenho» y de los «jogos de palavras» de los prosistas, y sobre todo de los poetas, añade una condena especial contra quienes escribieron y quisieron enseñar tales cosas, ejemplificándolas precisamente con el... infortunado Gracián :

«O pior está em que há homens que escreveram sobre a agudeza e quiseram ensinar isto aos leitores. Li há anos um livrinho pequeno de um Espanhol, que cuido era Gracián, e se intitulava Tratado de la Agudeza. Lembrome que o autor, no prólogo, desejava ao livro a boa fortuna de cair em maōs de quem o entendesse. Pelos meus pecados, eu fui um dos que não se cansaram em entendê-lo; porque logo entendi que o livro não merecia que se lesse.$^{8}$

5. O. cit., III, p. 114

6. O. cit., II, p. 146 .

7. O. cit., II, págs. 146-147.

8. O. cit., II, págs. 233-234. Verney completa este pensamiento suyo exponiendo sus propias ideas acerca de una antítesis entre el orden natural de las cosas y las aagudezas que serían, precisamente, por su naturaleza, artificio («querer ensinar a dizer graças e agudezas é o mesmo que querer ensinar a mudar a natureza: quem não é próprio para estas coisas, năo as pode aprender», etc.). 
Y de nuevo arremete contra El Criticón en la misma Carta (al tratar de los defectos especiales de las compusiciones poéticas portuguesas, y, concretamente, de las sátiras), colocando a su autor entre Persio y el escritor francés Barclai," en cuanto autores de sátiras "obscuríssimas" acusándolos a todos, desde luego, de no comprender ni siquiera ellos mismos lo que dicen, en varios pasajes de sus obras.

Este último reproche a Gracián aparece en el mismo pasaje en que Verney expresa, por explícito contraste, su propio placer en haber leído a Cervantes, cuya "história de D. Quijote» le parece «famosa e galante» (y añade: "gostei muito de a ler») e incluye a aquel escritor entre los mejores autores modernos que mejor aplicaron la oportuna finalidad de la sátira que es el "nâo repreender senão o que verdadeiramente é vicioso" "para instruir os nomens do que devem fugir", es decir incluyéndolo entre Sócrates y Horacio. ${ }^{10}$ Hay que añadir sin embargo que todo lo que dice Verney es eco casi literal de un pasaje de las Reflexions sur l'eloquence, la poétique, l'histoire et la philosophie (c. XxvıII) del P. René Rapin, del cual pasaje toma Verney, antes de lo que se refjere a Cervantes, las consideraciones generales sobre la sátira, con el juicio positivo acerca de Horacio y el juicio negativo acerca de Juvenal (considerado como declamatorio y poco conclusivo); y, por lo que se refiere a Cervantes, el escritor portugués se ha dejado probablemente influenciar por Rapin más benévolamente de lo que era su inclinación, como nos permite poder sospechar el hecho de que la opinión favorable que expresa sobre Don Quijote (tomada evidentemente de la interpretación, en clave teórica clasicista moralizadora, de Rapin), cuando Verney se halla frente a aquella obra, libre de influencias ajenas específicas, se atenúa y hasta se esfuma, llegando a ser sustituida por un estado de ánimo de cautela, si no de desconfianza. Todo esto lo había demostrado ya en la anterior Carta VI (en la que intentaba, como ya hemos recordado, hacer un plan de la retórica moderna), a propósito de los "ornamentos», en la cual, condenando la pésima moda de los escritores y poetas (que usan exclusivamente expresiones grandiosas para distinguirse de los comunes mortales, y que todo lo ven "gigantesco, ou para melhor dizer, tudo transformam»), añade, a modo de ejemplo comprobador, que «a sua cabeça é como a de D. Quixote, a quem moinhos pareciam palácios, e não havia coisa para ele que não fosse majestosa»; incluyendo luego implícitamente, por lógica consecuencia, también a Cervantes en la condena colectiva

9. Verdaderamente el francés de nacimiento Jean Barclay (muerto en Roma en 1621) -del cual Verney recuerda el Euphormio sive Satyricon, de 1603 - es considerado como inglés, pisesto que de hecho se inglesizó.

10. O. cit., II, p. 302 . 
contra todos estos poetas, los cuales «em lugar de engrandecerem quem fala, mostram a pobreza do seu entendimento, que, não tendo cabedal de dar palavras para tudo, pede-as emprestadas, ou furta sem advertência as que encontra». ${ }^{11}$

Y esta es una interpretación muy significativa del personaje cervantino, al cual se le quita así todo significado interior, de modo que queda reducido no a otra cosa que a una especie de monstruo formal (lo cual entra por lo demás - sea dicho de paso- en la conocida incapacidad, por parte del lector setecentista típico, de colocar y de ver al genio en la luz que le corresponde: recordemos, siempre por lo que se refiere a Cervantes, al P. Andrés, y a Bettinelli por lo que se refiere a Dante, o a Cândido Lusitano por lo que se refiere a Camões). Y es una interpretación, la de don Quijote como personaje, que queda confirmada un poco más adelante en el mismo capítulo sobre los "ornamentos", en el que el escritor, mofándose y definiendo ridículos los títulos setecentescos de obras y de colecciones (y comienza con la famosa portuguesa Fenix Renascida para recordar, entre otras, el Belerofonte literário de un enemigo del P. Feijoo a quien no nombra aquí pero que nombrará más adelante, es decir Salvador José Mañer), como complemento de su propia burla añade, a propósito de tales títulos, que «só estavam bem na boca de D. Quixote de la Mancha": ${ }^{12}$ lo cual, si de por sí podría interpretarse en un sentido no necesariamente desfavorable, en este momento de la exposición, y por el tono como se dice, asume un evidente matiz de escarnio.

En la Carta sobre la poesía, que es la séptima, en la cual esboza por vez primera una de sus ideas más avanzadas en relación con su época, es decir la de la conveniencia de usar la lengua portuguesa en lugar de la latina (convicción que será uno de los puntales de las propuestas de innovación pedagógica adelantadas por Verney en sus Cartas a este respecto), al recordar que grandes personalidades religiosas, incluso modernas, han compuesto versos en vulgar, cita, como único nombre, el de San Ignacio de Loyola (o. cit., II, p. 206). Y en otro momento de ideas audaces -naturalmente, por lo que a su época se refiere-, el momento en que propugna el derecho de la mujer a la instrucción (con una curiosa restricción por lo que se refiere a la música, que considera como no apta para ella) -en el Apêndice sobre o estudo das mulheres en la Carta XVI, sobre los «estudos»--, en implícito contraste con el pensamiento de Fénelon, a quien está siguiendo en aquel momento de

11. O. cit,, II, p. 89 .

12. O. cit., II, p. 116. 
su exposición, ${ }^{13}$ Verney estimula a las mujeres portuguesas para que aprendan y se perfeccionen "na Língua Espanhola, que serve muito para ler as histórias e outras obras daquela Nação": ${ }^{14}$ y queremos añadir que ésta es una manifestación, que podríamos decir indudablemente inesperada, de interés hacia España, aunque esto no ha de maravillarnos dada la normal amplitud de horizontes de Verney, ${ }^{15}$ amplitud de horizontes en la cual las zonas de sombra que se refieren a España se notan también en otros momentos de la exposición.

Efectivamente, en la bibliografía que Verney expone para el estudio de la Física (a la cual dedica la Carta X), en hasta veintitrés periódicos o enciclopedias de varios países no hay ninguna traza de España (están, junto a Portugal, Francia e Inglaterra, Italia y Rusia, Alemania y Holanda) (O. cit., III, págs. 224-226). En el largo discurso sobre las bibliografías referentes a los estudios de preparación para el estudio del derecho civil, y precisamente al de la filosofía (Carta XIII, dedicada a la cultura jurídica), en una larga lista de estudios (O. cit., IV, págs. 160-167) no hay ningún nombre español. En otros lugares, al hacer alguna rápida alusión a España o a los españoles, su juicio se orienta hacia la negación. Tal es en sustancia el caso de un pasaje de su discurso sobre la medicina, en la Carta XII, en la que Verney, atacando decididamente a los secuaces de Galeno, al citar ejemplos, pone sus ojos en España, ya en un sentido general ( Verdade é que em muitas partes, v. g. nas Espanhas, continuaram nesse tempo, e ainda no presente, os autores Galénicos»), ${ }^{16}$ ya en un sentido específico (para citar nombres de "Galénicos, que são capazes de facerem perder, não digo só a paciência, mas o juízo, e embrulharem a mesma Lógica Natural, quanto mais a Física, com os maus princípios que ensinam»,17 cita solamente un portugués, Bravo

13. Fénelon, en su Traité de l'éducation des filles que Verney seguía, habia desaconsejado, sin más, que Ias mujeres aprendiesen las lenguas italiana y española, que para ninguna otra cosa servirían, según èl, "qu'à lire des livres dangereux et capables d'augmenter les défauts des femrneśn (tomamos la cita del moderno editor de Verney, o. cit, V, p. 136, nota 1).

14. O. cit., V, p. 137 .

15. En la Carta anterior, la XV (sobre los estudios canónicos), hay otra indicación de cierto significado, aunque no se refiera a España en general sino a un español en particular, el jurisconsulto Esteban Daoiz (el benedictino de Panplona que vivió hasta 1619, canónigo en la catedral de su ciudad natal después de haber sido durante varios años Rector del Colegio de San Clemente en Bolonia), sobre cuya obra Verney se expresa en términos de absoluto elogio, y cuyo conocimiento declara necesario para los especialistas en la materia: "Para ter prontos os textos todos do Direito Canónico, nāo há welhor concordáncia que o Daoiz; ele traz todos us textos do Direito e das Glosas, por alfabeto; e é obra necessária para os que hāo-de estudar fundamentalmente, e ainda para os Advogados e Juízes que quere mter prontar as autoridades. Compôs também outra Concordáncia do Direito Civil» (O. cit., V, p. 42).

16. O. cit., IV, p. 37 .

17. O. cit, IV, p. 38. 
-João Bravo Chamiço-, y dos españoles, Vila Corta -Francisco Henríquez de Villacorta- y Heredia -Peđro Miguel Heredia-).

Un explícito cotejo, o una confrontación, entre españoles y portugueses sirve a veces a Verney para mostrar ciertas deficiencias de la cultura o de la índole ibérica comparadas con las de los demás pueblos europeos.

Siempre en las páginas sobre el P. António Vieira que sirven de apéndice a la Carta VI, burlándose del censor del primer tomo de las Cartas de aquel orador sagrado secentista, según el cual censor el mundo «deu (a Vieira) a coroa de Príncipe dos Oradores», para decir que aquél tiene horizontes mentales muy limitados, dice que «não fez maior jornada que de Lisboa a Madrid»: ${ }^{18}$ concepto, el de la limitación de horizontes de los ibéricos (aunque expresado sin acritud y sin intención de burla), que repite al final de este discurso sobre Vieira, cuando - después de haber establecido entre él y otros oradores sagrados (entre los cuales se cita expresamente sólo al italiano Segneri) la misma diferencia que hay entre la noche y el día- dice que se ve inducido a concluir «que quatro Portugueses ou Espanhóis, que dizem o contrário, não podem fazer mudar de conceito ao mundo inteligente.$^{19}$

Junta de nuevo a los dos pueblos - poniendo, mejor dicho, al español en el puesto de honor- cuando, al hablar de poesía, en la Carta VII, a propósito de los prejuicios sobre el arte de componer versos, lamentando cl que hasta entonces nadie se haya decidido a escribir una buena Arte poética portuguesa, acusa a sus propios compatriotas en estos términos:

«Todos se remedeiam com esta espanhola, que é muito má fazenda. Certo meu conhecido me mostrou há tempos uma manuscrita; mas nada mais era que um compêndio da dita espanhola, em que sòmente se trata das medidas dos versos e combinações de consonantes, o que está mui longe de se chamar Arte Poética.»20

Después de lo cual recarga la dosis sobre España:

«De não terem profundado a matéria, nascem todos os defeitos da Poesia, de que se acham infinitos na Espanha et tambén em Portugal..»1

Los pone, en cambio, juntos, siempre en esta Carta VII, en el reconocimiento de que «os Espanhóis e Portugueses mais advertidos fogem

\footnotetext{
18. O. cit., II, p. 185 .

19. O. cit., II, p. 189.

20. O. cit., II, págs. 203-204. António Salgado Júnior la identifica con el Arte poética española (1592) de Juan Díaz Rengifo, que tuvo muchísimas reproducciones con añadiduras en el Setecientos.

21. O. cit., II, p. 204.
} 
hoje» de los equívocos "que só reinaram no tempo de ignorância »22 (está disertando sobre las composiciones poéticas fundadas en la semejanza de letras, sílabas o palabras, y sobre la necesidad de claridad).

Siempre en esta Carta sobre la poesía cae bajo la pluma de Verney - y era inevitable que así fuera- uno de los temas que más da que pensar a los teóricos y a los hombres del Setecientos: el de la inverosimilitud en el arte. Y al demostrar la presencia de dicha inverosimilitud en la obra del portugués del Seiscientos Frei António das Chagas, mientras da la alarma sobre el peso de dichos defectos en cualquier género de manifestación poética (sea narrativa o dramática o épica), el discurso de Verney recae, también inevitablemente, sobre el teatro; en el cual teatro se lamenta de que pequen - de inverosimilitud- los portugueses y, aún más que ellos, los españoles que en este aspecto han sido sus maestros. Y sus ideas aquí son tan claras y precisas que vale la pena trancribir literalmente su pensamiento:

«Nas Comédias, pouco caem os Portugueses, porque não se aplicam a elas: raras vi, fora das de Camões; mas os Espanhóis caem muito nisto. Verá V. P. um pastor que fala com, mais filosofia e prudência que um Cipiāo Nasica ou Catão Uticense. Acham-se relaçōes com encaı cimientos tão despropositados, que não merecem outro nome que uma enfiada de manifestas mentiras. Algumas vezes, um homem vulgar faz uma décima ou oitava de repente; outras vezes, dá melhores conselhos que um consumado Jurisconsulto. Finalmente, em tudo se vê pintada a inverosimilidade. Não digo eu só Calderón, mas o mesmo D. António de Solís, que em outras coisas mostrou mais juízo que Calderón, nesta o perde. E finalmente todos os Espanhóis são o mesmo; porque tropeçam a cada passo na subtileza, que é imprópria na boca de semelhantes pessoas, e tambén imprópria de Comédia, que nada mais é que uma imagem da vida, proposta aos olhos dos homens, para repreender as acções ridículas dos mesmos. Dos Espanhóis o aprenderam os Portugueses. 23 $^{23}$

Ni siquiera Góngora tiene el honor de ser muy citado por Verney; y cuando lo recuerda lo hace como podía esperarse de un setecientista como Verney. Siempre en la Carta VII dedicada a la poesía, al hablar de los «defeitos particulares do Epigrama em Português: Décimas, Romances e Sonetos», atacando en general a los poetas que componen "Romances e coisas semelhantes com tal estudo, que não se entendem sem comentário", el estudioso portugués se basa sobre la Madre Juana de Méjico (es decir Sor Juana de la Cruz) y sobre Góngora, del cual cita expresamente los Romances, para pasar luego a los españoles en general

22, O. cit., II, p. 217.

23. O. cit., II, págs. 253-254. 
(«Finalmente, isto é defeito dos Espanhóis; e, dos que eu li, não achei algum que não pecasse nisto»); ${ }^{24} \mathrm{y}$ de aquí pasa a hablar de los portugueses con una fórmula que ha usado ya otras veces: «Dos Espanhóis o receberam os Portugueses ${ }^{25}$ e poucos são os que se exceptuaram»".

Poca cosa por lo que se refiere a Góngora... Pero en la misma Carta VII Verney ataca de nuevo a los españoles por otro motivo, es decir, acusándolos de haber traducido el poema de Camões no como poetas sino como versificadores $:^{27}$

«As versões espanholas nem menos concluem, porque foram feitas debaixo do mesmo clima. Os outros Estrangeiros que o louvam, fundam-se no que dizem os Espanhóis ou Portugueses, como V. P. pode observar; e alguns que chegaram a lê-lo, não dizem bem dele. $\aleph^{28}$

Que se consuelen, pues, los españoles ya que, como se ve, este severo setecentista portugués no hace cumplimientos ni siquiera con la poesía de su nación...

En la misma Carta VII otro argumento escocedor para España, en el Setecientos no menos que en los demás siglos, el del teatro, vuelve a ser tratado más adelante con un explícito ataque, aunque sin citar nombres, contra la comedia española, a la que acusa de no imitar a la naturaleza y de ser completamente esclava de «afectação e subtilezas» (estamos por tanto en la acostumbrada preocupación setecentesca de que el arte no peque de inverosimilitud), en explícita contradicción y en sustancial desventaja frente a la comedia italiana "mais natural». Son consideraciones que concluyen un discurso bastante largo que hace Verney para negar que la lengua española sea mejor que la portuguesa para el "poema dramático» (él condivide la opinión de gran parte de los entendedores de poesía, es decir que, a lo más, «toda a poesia soa melhor na língua italiana que noutra alguma»), ${ }^{29}$ y para rebatir dicha tesis se adentra en disquisiciones fonéticas, acabando por subrayar, en la preferencia que los portugueses mismos tienen por la lengua española en lo que se refiere al drama, la aversión hacia el teatro antiguo y la manía por el moderno, "de que parece ser sido inventor Lope de Vega»; teatro

24. O. cit., II, págs. 270-271.

25. Hemos vito que, en la misma Carta, a propósito del teatro, ha dicho: «Dos Espanhóis o aprenderam os Portugueses".

26. O. cit., II, p. 271.

27. A propósito de Os Lusíadas Verney, con su acostumbrada apertura de horizontes que lo lleva a subestimar más bien que a sobrestimar las producciones nacionales, se irrita de que el poema de Camöes sea puesto al lado de los de Homero sólo porque ha sido traducido a otras lenguas.

28. O. cit., II, p. 307.

29. O. cit., II, p. 323. 
moderno que - según Verney- gustaría precisamente porque está compuesto "de mil subtilezas e coisas semelhantes»: pero, de esta comedia española moderna, define, sin más, "mau» el estilo. ${ }^{30}$ Es la acostumbrada condena del teatro por parte de un setecentista intérprete del espíritu de su tiempo: condena explícita y total que recalca y confirma la formulada en el capítulo que ya hemos citado sobre la inverosimilitud, en el cual dicha condena tiene por blanco principal a Calderón, el perseguido por excelencia en aquella atmósfera de principios del Setecientos. ${ }^{31}$

Hay algún otro paso del Verdadeiro método de estudar en el que el autor cita juntos a españoles y portugueses para subrayar las características que él considera comunes a ambos pueblos: como en la Carta VIII (sobre la filosofía) en la que les atribuye en sumo grado el prejuicio de considerarse superiores a los demás pueblos ( Sei que a maior parte dos homens vive mui satisfeita dos estilos e singularidades do seu país; mas não sei se há quem requinte este prejuízo com tanto excesso como os Espanhóis e Portugueses"). ${ }^{32} \mathrm{Y}$ hay alguna otra Carta en la que, aun teniendo reproches que hacer, los hace en tono festivo: como en la Carta XV (dedicada al derecho canónico), en la que el autor, a propósito de ciertas ignorancias de los canonistas, se divierte burlándose de un abogado portugućs que, lleno de vanidad por cierta capacidad mnemónica que tenía pero ignorante en su disciplina, afirmaba seriamente que «Teologia somente se sabia na Espanha, e Direito em Portugal».33 Y hay en fin algún otro paso en el que Verney se muestra no muy entusiasta de la popularidad o de la influencia de las ideas de ciertos españoles en el ambiente cultural portugués: como en la Carta IX (sobre la metafísica), en la que, criticando la distinción entre metafísica intencional y metafísica real y atacando, a este respecto, a ciertos estudiosos a los que llama "meios-modernos», une al nombre del cartesiano francés Edmund

30. O. cit., II, págs. 323-324 passim.

31. Véase el trozo que hemos citado antes (n. 23), tomado de la o. cil., págs. 253-254. Por lo que se refiere a una interesante polémica, en pro y en contra de Calderón, que hubo en Portugal por aquellos mismos años, provocada por un Discurso apologético em defesa do teatro espanhol (1739) de Francisco Paulo de Portugal e Castro, véase: Alvaro Júlio da Costa Pimpāo, « La querelle clu théâtre espagnol et du theâtre fançais au Portugal, dans la première moitié du XVIIIe siècle*, en la "Revista de História Literaria de Portugal», año I (1962). Vol, 1, págs. 259-273.

32. O. cit., III, p. 16. A este respecto cuenta también Verney un episodio sucedido entre un florentino y un español de Amsterdam. El florentino hacía continuos elogios, precisos y especificos, de aquella ciudad mientras que el español permanecía obstinadamente mudo, hasta que el florentino exclama indignado: «só a um Espanhol nāo há-de agradar uma Cidade como Amesterdão, em que todos têm tanto que admirar?». Y el cspañol responde «mui lacónicon: «Vaya, para pintada!». Y comenta Verney: «Esta mesma resposta, com pouca diferença, me têm dado alguıns, em outras matérias. Quando se vêem obrigados com exemplos a reconhecer que os Estrangeiros lhe levarn considerável excesso, respondem rindo que assim é: mas que sòmente é em coisas inutilíssimas". (O. cit., III, p. 18).

33. O. cit., V, p. 19. 
Purchot - cuyo nombre y cuyas teorías aparecen frecuentemente en Verney -el nombre del oratoriano español Tomás Vicente Tosca (a quien corresponde el mérito de haber encaminado en direcciones modernas los estudios filosóficos de su Orden en España y también en Portugal a través de sus correligionarios portugueses); $;^{34}$ y en otro punto de su obra, en la Carta X (sobre la física, a propósito del estudio del hombre), llega Verney a aprobar, sin duda, el orden en que ambos autores, a los que cita nuevamente, disponen los estudios de física; pero desaprueba decididamente sus opiniones: «aqueles livros e outros semelhantes são os que não devem estudar os rapazes, pois têm mil suposições falsas e ensinam muito mau gosto de Filosofia». ${ }^{35}$

Pero hay también, finalmente, algún aspecto de la vida cultural española que place a Verney... En la Carta VIII (que estudia la lógica), en el paso en que, a propósito de la necesidad de ejemplificar las discusiones en torno a ciertos argumentos filosóficos, habla, además de los Universales, de los «Predicamentos», entre los peripatéticos «mais advertidos" que cita para corroborar su opinión (es decir, que es necesaria la ejemplificación) aparece el «Peripatético, e bom Peripatético, Soares Granatenses: aunque a Francisco Suárez lo ataca, y lo pone al lado del jesuíta Gregorio de Valencia (que fue profesor de teología en algunas Universidades alemanas en plena Reforma, contra la cual luchó), en la siguiente Carta IX (sobre la metafísica), acusando a entrambos de basarse en "prejuízos das Formas Escolásticas com outras iguais coisas violentíssimamente arrastradas p para sostener que la «Subsistência é uma Forma Peripatética distinta»; y llega al punto de comentar: "tanto é certo que a preocupação cega o juízo ». ${ }^{36}$ También en la anterior Carta VIII, sobre la filosofía, cita Verney a un jesuita español, Rodrigo de Arriaga (teólogo en Salamanca y en Valladolid), para corroborar su propia convicción sobre la inutilidad del uso del silogismo: "O P. Arriaga, no prólogo da sua Filosofia, diz claramente que não ditou muitas questões da forma Silogística, porque lhe pareceram escusadas; e que, havendo vinte anos que era mestre, nunca vira que pessoa alguma se servisse da Ponte dos Asnos para argumentar ou responder " ${ }^{37}$

Cada vez más raras son las citas o alusiones a españoles en las últimas Cartas, las que se refieren a problemas de medicina, de derecho civil o canónico, de teología, o de problemas de estudio de las diversas

\footnotetext{
34. o. cit., III, p. 117.

35. O. cit., III, págs. 237-238.

36. O. cit., III, págs. 149-150.

37. O. cit., III, p. 152.
} 
disciplinas. De ellas, la menos insignificante a este respecto es la XIII, sobre la cultura jurídica, en la que Verney aconseja leer, como óptimos comentadores de las Instituciones de Justiniano, al alemán Heinecke (a quien llama Heinécio) y al español António Pérez (que escribe Perezio), a quien sin embargo Verney considera holandés en un paso precedente 一o. cit., IV, p. $124-:^{38}$

«Eu não permitiria que o estudante lesse senão pelo Perézio, ou ainda melhor, pelo Heinécio, que escrevem uma breve paráfrase das
Intituiçoes.,39

Elogio de riqueza de doctrina que, en otro sentido, hace, en la Carta XIII que trata del derecho, a Martín del Río a quien cita entre los muchos extranjeros a quienes recuerda porque tuvieron conocimiento de otras disciplinas además de la que trataban oficialmente (para Martín del Río, la teología); mientras, por el contrario, en la misma Carta, ${ }^{40}$ censurando el pedantísimo trabajo de Jerónimo Zeballos, el Speculum Aureum, obra en cuatro pesados volúmenes de opiniones comunes recogidas de mala manera para ser contrapuestas a otras opiniones comunes, Verney transforma en juicio negativo (porque considera inútil tanta fatiga) el juicio positivo (en el sentido de que dicha obra demostraría lo inciertas que son las opiniones comunes) que había expresado Ludovico Muratori sobre Zevallos; ${ }^{41}$ mientras que toma de Muratori, y lo hace suyo, un posterior juicio positivo sobre el mismo autor español, a propósito de la oportunidad (concepto que se halla ya en Justiniano) de hacer uso muy cauto de los tratadistas y de los intérpretes de las leyes cuando se trata de aplicarlas. ${ }^{42}$

Una no disimulada ironía, más bien una flecha bastante maliciosa, lanza Verney en la que nos parece su última referencia a cosas de España, contra una clamorosa y obstinada disputa filosófica entre dominicos y jesuitas en tierras de España, la disputa sobre el libre albedrío; disputa que

"tendo nascido nas Espanhas, conservou sempre nelas os seus maiores apaixonados, que compuseram sobre ela tratados difusíssimos, que lhe impediu ocuparem-se em outras coisas necessárias. E, como a contenda sempre existe, dela nasceram infinitos volumes com que

\footnotetext{
38. Evidentemente, como ha hecho notar António Salgado Júnior, esto ocurrió porque Pérez se había formado en la escuela belga de Jurisprudencia.

39. O. cit., IV, p. 168.

40. O. cit,, IV, p. 188.

41. Verney ha parafraseado aquí o, más bien, traducido, un pasaje del capítulo IX de la obra muratoriana Dei Difetti della Giurisprudenza.

42. O. cit., IV, págs, 215-216.
} 
muitos autores têm cheio as livrarias, repetindo em longas páginas o que podiam dizer em breves palavras. ${ }^{43}$

(De la cual España habría pasado otro defecto a Portugal: «De que nasce que, cá em Portugal, onde tomam isto mais a peito, não se possam aplicar a outras coisas"-ibid.--). Y la flecha se repite inmediatamente después contra los escolásticos españoles:

«Pasma un homem quando vê os muitos volumes que compôs o Suares, o Vasques, os Salmanticenses etc. Contudo isso, examinandu bem o caso, o que eles dizem em tantos volumes escreveu em dois o Rhodes e o Comptono etc., e podia-se escrever ainda em menos. $n^{44}$

Pero nos complace el poder concluir esta ya demasiada larga y fastidiosa reseña (antes de pasar al hecho más específico y aquí, sin duda, más interesante) anotando que, en cambio, en la Carta siguiente, la XIV, sobre la teología, Verney, haciendo comprender su propio deseo de una reforma de la escolástica, sigue claramente la huella del pensamiento del dominico español Melchor Cano, aunque sin nombrarlo. ${ }^{45}$

Algunas de las dieciséis Cartas del Verdadeiro método de estudar tienen un apéndice: la III (sobre el latín) tiene un apéndice "sobre o valor de alguns latinistas portugueses"; la IV (sobre el griego y sobre el hebreo) tiene dos, uno «sobre a tradição dos estudos hebraísticos em Portugal»y otro "sobre o estudo das línguas modernas»; la VI (que es el plan de una métrica moderna) tiene un apéndice «sobre o valor da obra do P. António Vieira» - y es una fuerte crítica al más grande orador sagrado portugués-; y la IX (sobre la metafísica: es la penúltima acompañada de una adición antes del apéndice sobre los estudios concedidos a las mujeres, de la Carta XVI, de la cual hemos hablado ya en la página 9) tiene un apéndice que nos interesa aquí de modo particular: habla "sobre o valor da obra do P. Feijoo». Estas páginas, der tro de la subrayada escasa presencia de España en la gran obra de Verney, asumen por lo tanto un valor excepcional, tanto de hecho como de símbolo, no sólo por ser las únicas páginas dedicadas explícitamente a una personalidad de la cultura española sino también por tratarse de una personalidad más representativa que ninguna otra de la atmósfera de innovación que el Setecientos iba creando también en la Península Ibérica, aun dentro de aquellos moldes tradicionales en los cuales se mueve claramente el mundo de las ideas del P. Feijoo.

Y se podría pensar que Verney debería tener una actitud por lo

\footnotetext{
43. O. cit., IV, págs. 249-250.

44. O. cit., IV, págs. 250-251.

45. O. ck., IV, p. 283.
} 
menos sustancialmente benévola, si no precisamente entusiasta, hacia el P. Feijoo (que el estudioso portugués dice haber leído «haverá mais de doze anos»: evidentemente había leído el Teatro crítico, ya que las Cartas eruditas y curiosas, en la época de la publicación del Verdadeiro método, eran conocidas sólo en mínima parte), el cual se hallaba, como él, empeñado en la tarea de desenmascarar errores comunes y de impugnar diversas opiniones corrientes, como dice el mismo polemista español. En cambio, es sorprendente constatar que la realidad de las cosas es muy diferente.

El discurso de Verney sobre el P. Feijoo, de poquísimas páginas de imprenta, ${ }^{46}$ consta de un "juízo global doTeatro crítico", de una disquisición acerca del «valor dos Discursos sobre preconceitos e superstições" y de otra acerca del "valor dos Discurosos sobre matéria filosófica. Os seus Paradoxos físicos e matemáticos», y termina con una "conclusão". Con la acostumbrada ficción de responder a una carta de su supuesto interlocutor, Verney se apresura a precisar que no condena en absoluto a quien lea en Portugal al P. Feijoo, antes bien aconseja su lectura cuando se trate de... "pessoa ignorante, ou dos que não têm seguido os estudos ...pois achará ali muita coisa boa, que certamente não achará em livros portugueses»; pero se apresura igualmente a añadir que la obra del P. Feijoo puede ser perjudicial, y en todo caso es superflua, para un buen filósofo en acto o en potencia. En otras palabras, niega el que no se pueda ser personas doctas sin haber leído a Feijoo, y afirma que en todas las materias tratadas por él «qualquer homem de juízo dirá mesmo sem ter mais lido o Feijóo». Y ejemplifica esta inutilidad de Feijoo expresando la convicción de que no es en absoluto necesario que venga él a decirnos que es falso el proverbio vox populi vox dei, ya que «qualquer bom Filósofo, e que tenha um juízo claro, reconhece que não há conexão nenhuma entre a voz do Povo e a voz de Deus»: antes bien el filósofo - según Verney_ va mucho más allá que Feijoo, ya que "conhece fondamentalmente que a voz do Povo raríssimas vezes é a voz de Deus, e o ignorante tem mil exemplos diantes dos olhos que provam o mesmo».

Con la misma decisión niega Verney otras dos afirmaciones de Feijoo, «que estes espíritos foletos são arengas; que a idade dos homens não tem padecido coisa alguma ${ }^{47}$ (antes bien, Verney quita en sustancia el

46. En la edición Sá da Costa ocupa las páginas 158-165 del volumen III. Pero es necesario advertir que dichas páginas abundan en notas de António Salgado Júnior sobre Feijoo.

47. António Salgado Júnior hace derivar las dos afirmaciones de Feijoo, citadas por Verney, de los discursos sobre Duendes y Espiritus Familiares. (Discursos, t. III, n.o IV) y sobre Senectud del Mundo (O. cit,, I, XII). 
mérito de la segunda afirmación al escritor español para atribuir en cambio la precedencia de la misma al olivetano italiano Secondo Lancelloto, en la obra L'hoggidi..., cuyas dos partes aparecieron en 1623 y en los años 1658-1662). Y con los tres ejemplos que hemos citado considera Verney que ha demostrado suficientemente ser verdadero lo que afirma, es decir que «uma boa Lógica, aplicada a qualquer matéria, poupa todos aqueles discursos" (se entiende, del P. Feijoo). Aquella buena lógica - prosigue - que hace superfluo, antes bien desaconsejable, todo lo que Feijoo escribe también en torno a las "guerras filosóficas, modos de argumentar, etc.»; mejor dicho, puesto que Feijoo confiesa que es peripatético y que se encuentra muy bien con las «Formas Aristotélicas», «isto basta para o canonizar e saber que, nem na Lógica, nem na Física, pode discorrer bem». Y de nuevo recomienda Verney mucha cautela tanto a quien lea las páginas de Feijoo sobre la física, donde se hallarían "alguns erros gordos", como a quien tome nota de sus Paradojas, en muchas de las cuales "engana-se, e diz erros"; de las cuales paradojas deduce sin más Verney que Feijoo "nada sabe de Matemática» y «não sabendo, pois, Matemática, como é possivel que discorra bem na Física?».

Pero lo que precede no es lo peor sobre el P. Feijoo. Lo peor está en la conclusión de Verney, que conviene leer íntegramente:

"Alguma coisa que diz menos má é o que leu nas Colecções das Academias Régias, buscando materiais para o seu Teatro. Mas isto ou é muito pouco, ou, ainda que o explicasse bem, quem lê Filosofia escusa o dito Feijóo. Com efeito, o Feijóo só agrada aos ignorantes; os homens verdadeiramente doutos, ou, ao menos, de juízio claro, deixam a sua lição aos idiotas; mas não se servem de tal livro. Nem eu o aconselho, por não embrulhar as ideias da mente, e originar confusões.»

(Y si alguien creyera que Verney juzga así a Feijoo por estar acaso influenciado por el antagonista de aquél, el otro español Mañer, que se desengañe:

"Nem cuide V. P. que digo isto pelo ter lido no seu antagonista Mañer. Não senhor; mas pelo que me lembra do dito autor e a razão me persuade ser assim. Também do Antagonista formo o mesmo conceito: repreendeu algumas coisas bem; mas também, porque não entendia as matérias, disse muita parvoíce.p

Y concluye así :

«Isto é o que me ocorre dizer por agora; com mais vagar explicarei o restante»,

que no nos consta, desgraciadamente, que haya explicado después). 
Llegados a este punto, pasamos el interesante problema de indagar los motivos de tan severa desvalorización de Feijoo por parte de Verney, a los colegas estudiosos del pensamiento del Setecientos. Los juicios negativos de Verney son siempre abiertamente explícitos. El juzga sin restricciones mentales y sin reticencias; pero en este caso, en las páginas sobre el P. Feijoo, nos parece observar cierto nerviosismo, cierta falta de autocontrol, la cual no es normal en el erudito pensador portugués. ¿Habrá bastado cualquier diversidad de pensamiento, como la de un Feijoo secuaz de las «formas aristotélicas», para que Verney se le oponga con el tono con que se le opone? Nos parece que se puede razonablemente dudar de ello, y tampoco nos parece que se pueda admitir, ni siquiera en forma de hipótesis, que Verney quisiera a toda costa atacar a un español cualquiera, para vengarse por haber sido "principalment l'objet des railleries díun Ecrivain Espagnol, dont le Journal Etranger, d'Avril 1760 , a fait connaître une Satyre assez piquante», como dice Verney mismo en su traducción francesa de la Advertencia que puso al principio de la Synopsis de su propia obra; ${ }^{48}$ tanto más cuanto que en la misma Advertencia subraya la buena acogida que había tenido su obra en España:

«Les traits que le P. Isla, J. a semés dans sa burlesque Histoire du Frère Gerondif ou Gerundio, n'ont point empêché la Nouvelle Méthode d'être très bien reçue en Espagne, puisqu'en 1760 elle a été traduitc en Langue Castillane par le Docteur Joseph Maymo y Ribès, Avocat des Conseils Royaux, et imprimée à Madrid.»

Y la alusión al Padre Isla, después de la noticia anterior sobre un no precisado "Ecrivain Espagnol», es de tal naturaleza que no excluye la hipótesis de que los dos sean la misma persona, cuya "Satyre assez piquante» no habría desagradado en el fondo a Verney. Pero dejamos abierto también este problema secundario (el de la identificación o no del autor no nombrado, en el no precisado periódico, con el Padre Isla), problema secundario en el conjunto del otro problema mayor antes aludido, es decir el de los motivos de la actitud no sólo excepcionalmente desfavorable sino también abiertamente áspera, de Verney frente a Feijoo, limitándonos a observar que éste último, objetivo y sereno cuando juzga también las cosas de Portugal, ${ }^{49}$ no tuvo mucha fortuna con uno de los portugueses más inteligentes y más representativos de su época.

48. O. cit., V, p. 155 .

49. Creemos haberlo demostrado en Portogallo e portoghesi in pagine di padre Feijóo en la Miscelânea de Estudos a Joaquim de Carvalho, Figueira da Foz, N.o 4, 1960, págs. 382-393. 